\title{
BMJ Open Factors influencing the diagnostic accuracy of the rapid influenza antigen detection test (RIADT): a cross-sectional study
}

\author{
Mika Tanei, ${ }^{1}$ Hirohide Yokokawa, ${ }^{1}$ Kenji Murai, ${ }^{1}$ Rino Sakamoto, ${ }^{1}$ Yu Amari, ${ }^{1}$ \\ Soushin Boku, ${ }^{1}$ Akihiro Inui, ${ }^{1}$ Kazutoshi Fujibayashi, ${ }^{1}$ Yuki Uehara, ${ }^{1,2}$ \\ Hiroshi Isonuma, ${ }^{1}$ Ken Kikuchi, ${ }^{1,2}$ Toshio Naito ${ }^{1,2}$
}

To cite: Tanei M,

Yokokawa $\mathrm{H}$, Murai $\mathrm{K}$, et al. Factors influencing the diagnostic accuracy of the rapid influenza antigen detection test (RIADT): a cross-sectional study. BMJ Open 2014;4: e003885. doi:10.1136/ bmjopen-2013-003885

- Prepublication history and additional material for this paper is available online. To view these files please visit the journal online (http://dx.doi.org/10.1136/ bmjopen-2013-003885).

Received 2 September 2013 Revised 14 November 2013 Accepted 22 November 2013

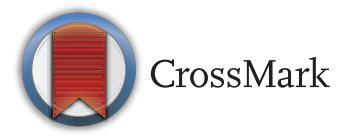

${ }^{1}$ Department of General Medicine, Juntendo University School of Medicine, Tokyo, Japan ${ }^{2}$ Department of Infection Control Science, Juntendo University Faculty of Medicine, Tokyo, Japan

Correspondence to Dr Toshio Naito; naito@juntendo.ac.jp

\section{ABSTRACT}

Objective: To evaluate the diagnostic accuracy of the rapid influenza antigen detection test (RIADT) and determine which symptoms are relevant to results.

Design: Single-centre, cross-sectional study.

Setting: Primary care centre, Tokyo, Japan.

Participants: 82 consecutive outpatients presenting with upper respiratory symptoms and fever $\geq 37^{\circ} \mathrm{C}$ at any time from symptom onset, between December 2010 and April 2011.

Main outcome measures: Results of history and physical examination including age, sex, temperature, time of test from symptom onset, vaccination record and current symptoms (sore throat, arthralgia and/or myalgia, headache, chills, cough and/or throat phlegm, nasal discharge) were recorded. The RIADT and a fully automated respiratory virus nucleic acid test (Verigene Respiratory Virus Plus; VRV), the latter being the gold standard, were performed. Patients were divided into four groups: false negative (FN), RIADT- and VRV+; true positive (TP), RIADT+ and VRV+; true negative (TN), RIADT - and VRV-; and false positive, RIADT+ and VRV-. Groups were compared regarding age, sex, temperature, time of test from symptom onset, vaccination record and symptoms.

Results: RIADT sensitivity, specificity, positive predictive value and negative predictive value were $72.9 \%$ (95\% Cl $61.5 \%$ to $84.2 \%$ ), $91.3 \%$ (79.7\% to $102.8 \%), 95.6 \%(89.5 \%$ to $101.6 \%)$ and $56.8 \%$ $(40.8 \%$ to $72.7 \%)$, respectively. Time from symptom onset to test was shorter for the FN group than the TP group ( $p=0.009$ ). No significant differences were detected for the other factors assessed. Results revealed higher temperatures for FN than TN patients $(p=0.043)$, and more FN than TN patients had chills $(\mathrm{p}=0.058)$.

Conclusions: The RIADT sensitivity was low, due to early administration of the test. In the epidemic season, the RIADT should not be used for suspected influenza until $12 \mathrm{~h}$ after symptom onset. A positive RIADT firmly supports the influenza diagnosis; a negative result does not confirm its absence. High fever and chills might indicate influenza, but additional tests are sometimes necessary.

\section{Strengths and limitations of this study}

- Influenza is one of the most common diseases that general physicians see clinically. The rapid influenza antigen detection test (RIADT) is helpful for diagnosis, but its low sensitivity is sometimes misleading, resulting in underdiagnosis. We aimed to evaluate the diagnostic accuracy and characteristics of the RIADT and determine which symptoms are relevant to the results. Our findings may help general physicians when using the RIADT.

- Clinically, the sensitivity of RIADT is relatively low and the specificity is high; current results confirm this. Testing too early could be a factor increasing false negative results. For patients presenting with high fever and upper respiratory symptoms soon after onset, RIADT should not be used.

- The presence of high fever and chills may be helpful indicators of influenza, even if the RIADT result is negative, but additional examination is necessary for patients with symptoms inconsistent with influenza virus infection.

- The high specificity of the RIADT means that a positive result provides firm support for the diagnosis of influenza.

- The following limitations need to be acknowledged. First, the 82 participants enrolled in the current study were relatively young and healthy. Second, the reference or 'gold' standard in this study was not viral culture or reverse transcriptase-PCR, but the Verigene System Verigene Respiratory Virus Plus, which detects influenza virus nucleic acid.

\section{INTRODUCTION}

Influenza is a rapid-onset systemic illness caused by the influenza virus; patients present with high fever, chills, cough, myalgia, sore throat and headache. ${ }^{12}$ Previously, the diagnosis was made from these symptoms. ${ }^{3-6}$ However, since their introduction to Japan in 1999, rapid influenza antigen detection tests 
(RIADTs) using immunochromatography have dramatically changed the influenza diagnostic procedure..$^{7} 8$ Before the introduction of RIADTs and anti-influenza drugs, physicians told patients to stay home if they had no suspected complications. Now physicians use RIADTs to diagnose influenza and therefore can prescribe antiviral drugs soon after symptom onset. ${ }^{8-13}$ Making the distinction between the flu and other respiratory diseases serves to improve individual care management. ${ }^{14-16}$ Detection of influenza virus can reduce inappropriate antibiotic use, guide antiviral therapy and decrease use of other laboratory studies and healthcare costs. ${ }^{14}$ Currently, many RIADTs are available; their sensitivities and specificities have improved and their usefulness has been widely recognised. ${ }^{17}$ RIADTs help physicians to diagnose influenza during epidemics, but the RIADT results make it difficult to diagnose flu during periods of transition from epidemic to non-epidemic times, or when patients present with atypical symptoms. ${ }^{17} 18$

For example, when patients' flu-like symptoms are typical of influenza but the RIADT results are negative, whether or not the patient actually has influenza is unclear. Physicians may question whether samples were obtained correctly or whether the result is a false negative $(\mathrm{FN})$, and may hesitate to prescribe anti-influenza drugs.

According to a meta-analysis reported in 2012, the pooled RIADT sensitivity was $62.3 \%$ (95\% CI $57.9 \%$ to $66.6 \%$ ), and specificity was $98.2 \%$ (95\% CI $97.5 \%$ to $98.7 \%) .{ }^{19}$ Thus, the specificity is very high but the sensitivity is relatively low. Several factors affecting the results of RIADTs have been reported, but some remain controversial. ${ }^{19} 20$

This study was designed to evaluate the diagnostic accuracy and characteristics of one RIADT, the RapidTesta FLUII (Sekisui Medical, Tokyo, Japan), and to determine which symptoms are associated with the results obtained. In addition, we sought to identify predictors of influenza for patients with FN RIADT results.

\section{METHODS}

From December 2010 to April 2011, during the influenza epidemic season in Japan, ${ }^{21}$ participants were enrolled in the Departments of General Medicine of Juntendo University Hospital and Juntendo University Nerima Hospital, both in Tokyo, Japan. Consecutive cases were enrolled that met the following inclusion criteria: adult patients presenting with any upper respiratory symptoms, and fever $\geq 37^{\circ} \mathrm{C}$ at any time after symptom onset. All of the participants were physically examined and historical data including age, sex, vaccination status, temperature and symptoms (sore throat, arthralgia and/or myalgia, headache, chills, cough and/ or throat phlegm and nasal discharge) were recorded, as was the time to test from symptom onset. Vaccination status indicated whether or not an influenza vaccine had been administered during that season before symptom onset. The temperature was taken on presentation by an outpatient physician. Symptoms recorded were those participants reported on presentation. Only a few patients had taken antipyretics and their temperature was around $36^{\circ} \mathrm{C}$, but we could not analyse the data with regard to antipyretics use. All were tested by the RIADT and a fully automated respiratory virus nucleic acid test, Verigene Respiratory Virus Plus (VRV; NanoSphere, Chicago, Illinois, USA), the latter being the gold standard for this study. Based on the test results, patients were divided into four groups, as follows: FN, RIADT- and $\mathrm{VRV+}$; true positive (TP), RIADT+ and VRV+; true negative (TN), RIADT - and VRV-; and false positive (FP), RIADT + and VRV-. The sensitivity, specificity, positive predictive value (PPV) and negative predictive value (NPV) of the RIADT were calculated. In order to ascertain the cause of false-negative results and to find a predictor of influenza, comparisons were made between pairs of groups (FN vs $\mathrm{TP}$ and then $\mathrm{FN}$ vs $\mathrm{TN}$ ) with respect to age, sex, vaccination status, time from symptom onset to test, temperature and symptoms.

\section{Laboratory confirmation}

Two nasopharyngeal specimens were collected from each patient by a physician, using sterile cotton swabs, following the procedure detailed in the RIADT manufacturer's package insert.

\section{Rapid influenza antigen detection test}

RIADTs are immunoassays using the antigen-antibody reaction, based on colloidal gold immunochromatography. The test results are checked visually. The RIADT used for this study, the RapidTesta FLU II, requires a $1 \times 10^{5}$ tissue-culture infective dose (TCID) $)_{50}$ per $\mathrm{mL}$ for type A influenza, and $1.2 \times 10^{5} \mathrm{TCID}_{50} / \mathrm{mL}$ for type B influenza, to produce a positive result. ${ }^{22}$ RIADT was performed using one of the nasopharyngeal specimens, according to the manufacturer's instructions. In brief, samples were diluted in the medium immediately, and then dripped into the test device. Results were determined 15 min after the test start. When influenza A or B is present, an additional red line appears next to the control red line on the letter ' $\mathrm{A}$ ' or ' $\mathrm{B}$ ' indicated on the test device. The procedures were performed by outpatient physicians and residents who had been well trained in the technique.

\section{Fully automated respiratory virus nucleic acid test}

The second nasopharyngeal swab was immediately placed into Universal Viral Transport medium (UTM; Becton Dickinson, Tokyo, Japan) and tested by the Verigene System within $24 \mathrm{~h}$. The system uses a multiplexed microarray-based technology. A nucleic acid detection cartridge named VRV Nucleic Acid Test was selected, which could detect the following influenza viruses: A (H1N1), A (H3N2), pandemic 2009 influenza A (H1N1), influenza B virus and respiratory syncytial 
virus (A, B). This system was approved by the US Food and Drug Administration (FDA) in May 2009. ${ }^{23}$

Specimens were tested by Verigene test according to the manufacturer's instructions by the physician attending the study patients. Briefly, the test cartridge was preloaded with wash solutions, oligonucleotide probe solution and signal amplification solution. The extraction tray, amplification tray and test cartridge were then loaded onto the Verigene System. Following the addition of $200 \mu \mathrm{L}$ of UTM containing materials expressed from the nasopharyngeal swabs, the analysis began; this consisted of a programmed, totally automated extraction, reverse transcriptase-PCR (RT-PCR) and hybridisation sequence. The final readout of the microarray was made by the insertion of the slide array into a reader. ${ }^{24}$ The result for each virus type, 'Detected' or 'Not detected,' was displayed on a monitor. Approximately $2.5 \mathrm{~h}$ was required from sample procurement to final readout.

Specimen collection was performed by one of five physicians, who also read the results. These physicians were trained by an instructor from the manufacturer before the study started.

\section{Statistical analysis}

The sensitivity, specificity, PPV and NPV of the RIADT used were determined using standard methods. Statistical analyses were performed using statistical software package, STATA SE V.12 (StataCorp LP, College Station, Texas, USA). Continuous variables (age, the time from symptom onset and temperature) were analysed by the Wilcoxon rank sum test, and the Fisher's exact test was used for comparing patient sex, vaccination status and symptoms. Significance was assigned to results having $\mathrm{p}$ values $<0.05$, and borderline significance was assigned to $\mathrm{p}$ values $>0.05$ and $<0.10$.

\section{Results}

A total of 82 consecutive patients meeting eligibility criteria were enrolled from December 2010 to April 2011 (Juntendo University Hospital: 37 patients; Juntendo University Nerima Hospital: 45 patients). There was no selection discretion on the part of the attending physicians. Table 1 shows characteristics for all patients. The median age was 30.5 (range 20-63) years, and $42.7 \%$ $(35 / 82)$ were men. During the 2010/2011 flu season, $48.8 \%(40 / 82)$ of the patients were vaccinated for influenza. The average time from symptom onset to diagnostic test was $18.9 \pm 17.2 \mathrm{~h} ; 13.4 \%(11 / 82)$ came to the hospital within $6 \mathrm{~h}$ from symptom onset and $72 \%(59 / 82)$ within $24 \mathrm{~h}$.

Table 2 shows the RIADT and VRV results as well as the RIADT accuracy. By RIADT results, 54.9\% (45/82) of patients were positive and the other $45.1 \%(37 / 82)$ were negative. By VRV results, $72.0 \%$ (59/82) were positive and the other $28.0 \%(23 / 82)$ were negative. Dividing them into four groups, the number of patients in each group was: FN, 16; TP, 43; TN, 21 and FP, 2. The prevalence of influenza A or B virus infection was $72 \%$. When

\begin{tabular}{|c|c|}
\hline Patient characteristics & $\mathbf{N}(\%)$ \\
\hline \multicolumn{2}{|l|}{ Age (years) } \\
\hline \multicolumn{2}{|c|}{ Median 30.5, range 20-63 } \\
\hline$<30$ & $37(45.1)$ \\
\hline $30-49$ & $36(43.9)$ \\
\hline$\geq 50$ & $9(11.0)$ \\
\hline Male sex (\%) & $35(42.7)$ \\
\hline Vaccination status (\%) & $40(48.8)$ \\
\hline \multicolumn{2}{|c|}{ Time to test from symptom onset (hours) } \\
\hline \multicolumn{2}{|l|}{ Mean $18.9 \pm 17.3$} \\
\hline$<6$ & $11(13.4)$ \\
\hline $6-12$ & $14(17.1)$ \\
\hline $12-24$ & $34(41.5)$ \\
\hline $24-48$ & $13(15.8)$ \\
\hline$\geq 48$ & $9(11.0)$ \\
\hline Unnknown & $1(1.2)$ \\
\hline
\end{tabular}

the VRV test was used as the gold standard, the RIADT sensitivity, specificity, PPV and NPV were $72.9 \%$ (95\% CI $61.5 \%$ to $84.2 \%), 91.3 \%(79.7 \%$ to $102.8 \%), 95.6 \%$ $(89.5 \%$ to $101.6 \%)$ and $56.8 \%(40.8 \%$ to $72.7 \%)$, respectively.

Tables 3 and 4 show the patients' clinical characteristics and presenting symptoms by group. One patient was excluded from the FN group due to development of bacterial pneumonia $72 \mathrm{~h}$ after presenting with a high fever. No significant differences were found in age, sex and vaccination status among the $\mathrm{FN}, \mathrm{TP}$ and $\mathrm{TN}$ groups. The time from symptom onset to test was significantly earlier in the FN group compared with the TP group $(11.4 \pm 10.9$ vs $22.0 \pm 17.3 \mathrm{~h}, \mathrm{p}=0.009)$. However, no significant differences between these groups were found for the other factors and symptoms assessed. The FN and $\mathrm{TN}$ groups were compared in order to reveal any differences in diagnostic factors or symptoms. The temperature of the FN negative group was higher than the TN group ( $38.2 \pm 0.8$ vs $37.6 \pm 0.8, p=0.043)$. More patients presented with chills in the FN group $(7 / 15$ vs $3 / 21$,

\begin{tabular}{|c|c|c|c|}
\hline & \multicolumn{2}{|l|}{ RIADT } & \multirow[b]{2}{*}{ Total } \\
\hline & $\mathrm{A}(+)$ and/or $\mathrm{B}(+)$ & $(-)$ & \\
\hline \multicolumn{4}{|c|}{ Verigene test (VRV) } \\
\hline Positive & 43 & 16 & 59 \\
\hline Negative & 2 & 21 & 23 \\
\hline Total & 45 & 37 & 82 \\
\hline \multicolumn{4}{|c|}{$\begin{array}{l}\text { Prevalence: } 72 \% \text {. } \\
\text { Sensitivity: } 72.9 \% \text { ( } 95 \% \mathrm{Cl} 61.5 \% \text { to } 84.2 \%) \text {. } \\
\text { Specificity: } 91.3 \%(95 \% \mathrm{Cl} 79.7 \% \text { to } 102.8 \%) \text {. } \\
\text { PPV: } 95.6 \%(95 \% \mathrm{Cl} 89.5 \% \text { to } 101.6 \%) \text {. } \\
\text { NPV: } 56.8 \%(95 \% \mathrm{Cl} 40.8 \% \text { to } 72.7 \%) \text {. } \\
\text { NPV, negative predictive value; PPV, Positive predictive value; } \\
\text { RIADT, rapid influenza antigen detection test; VRV, Verigene } \\
\text { Respiratory Virus Plus. }\end{array}$} \\
\hline
\end{tabular}


Table 3 Patient characteristics by group

\begin{tabular}{|c|c|c|c|c|c|}
\hline \multirow[b]{2}{*}{ Patient characteristics } & \multirow[b]{2}{*}{ FN group $(n=15 t)$} & \multirow[b]{2}{*}{ TP group $(n=43)$} & \multirow[b]{2}{*}{ TN group $(n=21)$} & \multicolumn{2}{|l|}{ p Value } \\
\hline & & & & FN vs TP & FN vs TN \\
\hline \multicolumn{6}{|l|}{ Age in years } \\
\hline Median & 31 & 30 & 29 & 0.880 & 0.653 \\
\hline Range & $20-57$ & $21-62$ & $23-63$ & & \\
\hline Age distribution (years) & n (\%) & n (\%) & n (\%) & & \\
\hline$<30$ & $6(40.0)$ & $19(44.2)$ & $11(52.4)$ & & \\
\hline $30-49$ & $6(40.0)$ & $20(46.5)$ & $8(38.1)$ & & \\
\hline$\geq 50$ & $3(20.0)$ & $4(9.3)$ & $2(9.5)$ & & \\
\hline Male sex & $7(46.7)$ & $17(39.5)$ & $9(42.9)$ & 0.763 & 1.000 \\
\hline Vaccination status & 5 (33.3) & $22(51.2)$ & 13 (61.9) & 0.368 & 0.176 \\
\hline \multicolumn{6}{|l|}{$\begin{array}{l}\text { Time to test from symptom } \\
\text { onset (hours) }\end{array}$} \\
\hline Mean & $11.4 \pm 10.9$ & $22.0 \pm 17.3$ & $15.7 \pm 16.8$ & $0.009^{*}$ & 0.449 \\
\hline $\begin{array}{l}\text { Time to test from symptom } \\
\text { onset (hours) }\end{array}$ & n (\%) & n (\%) & n (\%) & & \\
\hline$<6$ & $3(20.0)$ & $4(9.3)$ & $2(14.3)$ & & \\
\hline $6-12$ & $6(40.0)$ & $6(14.0)$ & $2(9.5)$ & & \\
\hline $12-24$ & $5(33.3)$ & $16(37.2)$ & $11(52.4)$ & & \\
\hline $24-48$ & $0(0.0)$ & $11(25.6)$ & $2(9.5)$ & & \\
\hline$\geq 48$ & $1(6.7)$ & 6 (14.0) & 2 (9.5) & & \\
\hline Unknown & $0(0.0)$ & $0(0.0)$ & $1(4.8)$ & & \\
\hline
\end{tabular}

$\mathrm{p}=0.058$ : borderline significance). No other significant differences were found in symptoms.

Combining the RIADT result and presence of temperature $\geq 37.8^{\circ} \mathrm{C}$ or chills increased the sensitivity and the NPV from $72.9 \%$ to $96.6 \% \quad(95 \%$ CI $92.0 \%$ to $101.2 \%)$ and from $56.8 \%$ to $90.5 \%$ ( $77.9 \%$ to $103 \%)$, respectively. The specificity and the PPV were $82.6 \%$ $(67.1 \%$ to $98.1 \%)$ and $93.4 \%(87.2 \%$ to $99.7 \%)$, respectively.

\section{DISCUSSION}

Rapid influenza antigen detection tests

Influenza virus infection is confirmed by virus isolation, viral nucleic acid detection (eg, by RT-PCR) or detecting a rising serum antibody titre in the acute and convalescent period. ${ }^{19} 232526$ However, these tests are time consuming and costly, so they are rarely used clinically in Japan. ${ }^{24}$ Before introduction of RIADTs to Japan in 1999, physicians diagnosed

Table 4 Symptoms and clinical characteristics at presentation

\begin{tabular}{|c|c|c|c|c|c|}
\hline \multirow[b]{2}{*}{ Patient characteristics } & \multirow[b]{2}{*}{ FN group $(n=15 t)$} & \multirow[b]{2}{*}{ TP group $(n=43)$} & \multirow[b]{2}{*}{ TN group $(n=21)$} & \multicolumn{2}{|l|}{ p Value } \\
\hline & & & & FN vs TP & FN vs TN \\
\hline \multicolumn{6}{|l|}{ Temperature $\left({ }^{\circ} \mathrm{C}\right)$} \\
\hline Mean & $38.2 \pm 0.8$ & $38.0 \pm 0.7$ & $37.6 \pm 0.8$ & 0.593 & $0.043^{\star}$ \\
\hline Temperature $\left({ }^{\circ} \mathrm{C}\right)$ & n (\%) & n (\%) & n (\%) & & \\
\hline$\leq 37.4$ & 2 (13.3) & $8(18.6)$ & $9(42.9)$ & & \\
\hline 37.5 to 38.0 & 5 (33.3) & 15 (54.9) & 7 (33.3) & & \\
\hline$\geq 38.1$ & 8 (53.3) & $20(46.5)$ & $5(23.8)$ & & \\
\hline \multicolumn{6}{|l|}{ Symptoms } \\
\hline Sore throat & $11(73.3)$ & $32(74.4)$ & $14(66.7)$ & 1.000 & 0.729 \\
\hline Arthralgia/myalgia & $6(40.0)$ & $22(51.2)$ & $10(47.6)$ & 0.554 & 0.741 \\
\hline Headache & $7(46.7)$ & $13(30.2)$ & $6(28.6)$ & 0.345 & 0.310 \\
\hline Chills & $7(46.7)$ & $16(37.2)$ & $3(14.3)$ & 0.553 & $0.058^{\star \star}$ \\
\hline Cough/throat phlegm & $9(60.0)$ & $25(58.1)$ & $10(47.6)$ & 1.000 & 0.516 \\
\hline Nasal discharge & $2(13.3)$ & 15 (34.9) & $6(28.6)$ & 0.118 & 0.424 \\
\hline
\end{tabular}


influenza by assessing clinical symptoms and epidemiological information.

RIADTs are widely used nowadays, because they are simple, inexpensive and require no special facilities, equipment or technology. ${ }^{27}$ Use of RIADTs can decrease unnecessary blood tests, imaging studies and antibiotic use.

According to our RIADT correlative examination results for type A influenza, the sensitivity is $94.3 \%$ and specificity is $97.8 \%$, and the values for type B influenza are $87 \%$ and $100 \%$, respectively, referencing results of virus culture and PCR. ${ }^{22}$ Clinically, the specificity is high but the sensitivity is low. Reported factors which lower the sensitivity are the following: type B influenza virus, pandemic 2009 influenza A (H1N1) virus, the timing of the test, use in adult patients, low fever, small amounts of sample, prior vaccination and poor sampling technique. ${ }^{19} 20$

\section{Time from symptom onset to the test}

In the current study, the mean time from symptom onset to test in the FN group was $11.4 \pm 10.9 \mathrm{~h}$, and 22.0 $\pm 17.3 \mathrm{~h}$ in the TP group. The FN group was tested significantly earlier than the TP group $(p=0.009)$. This suggests that testing too early is a factor increasing FN results, a finding that is consistent with a previous report. ${ }^{19}$

The RIADT used for this study, the RapidTesta FLU II, requires a $1 \times 10^{5} \mathrm{TCID}_{50} / \mathrm{mL}$ for type $\mathrm{A}$ influenza, and $1.2 \times 10^{5} \mathrm{TCID}_{50} / \mathrm{mL}$ for type B influenza, to produce a positive result. The influenza virus proliferates in respiratory tract epithelial cells and appears in respiratory secretions $24 \mathrm{~h}$ before symptom onset. The peak of viral shedding is $24 \mathrm{~h}$ after symptom onset, and then the virus load decreases rapidly. ${ }^{28}$ In the current study, we assumed that the amount of virus in the FN group was less than that in the TP group.

\section{Symptoms}

The report of a systematic review from 2004 regarding the clinical diagnosis of influenza states that the medical history and physical examination findings of rigour, fever and sweating are best for positive influenza diagnosis (likelihood ratios $+7.2,+4$ and +3 , respectively). ${ }^{29}$ Fever was defined as a temperature $\geq 37.8^{\circ} \mathrm{C}$ or higher. ${ }^{2}$ In the current study, the temperature of the $\mathrm{FN}$ group was significantly higher than that of the TN group (38.2 \pm 0.8 vs $37.6 \pm 0.8, p=0.043$ ), but no significant difference of temperature was detected between the $\mathrm{FN}$ and TP groups $(38.2 \pm 0.8$ vs $38.0 \pm 0.7, \mathrm{p}=0.593)$. This indicates that the temperature of patients with influenza is relatively high. It should be noted that, even if RIADT is negative, it is possible that patients presenting with high fever have influenza.

A previously reported prospective cohort study revealed the relationship between chills and bacteraemia: chills were divided into four categories of none, mild, moderate and severe, and a greater degree of chills suggested a higher risk of bacteraemia. ${ }^{30}$ We did not categorise chills, but found that the FN group had more chills than did the $\mathrm{TN}$ group. The $\mathrm{p}$ value of 0.058 , as 'borderline significant', was caused by having an insufficient number of participants. The presence of chills is also thought to be an indicator of influenza if the RIADT result is negative.

The positive RIADT result gives physicians firm support for the diagnosis of influenza because of the high specificity of this test, but a negative result does not confirm its absence. Presence of high fever and chills is indicative of influenza, but if patients' presenting symptoms are inconsistent with influenza or acute upper respiratory infection, additional studies are necessary to make an accurate diagnosis. High fever with moderate to severe chills sometimes indicates bacteraemia or other bacterial infection. ${ }^{30}$

\section{Limitations}

The 82 participants enrolled in the current study were relatively young and healthy. This is because our hospitals are located in central Tokyo and most of the patients are young or middle-aged healthy workers. We did not exclude elderly patients or patients with comorbid diseases. Elderly people tend to present with atypical symptoms and often have underlying primary illnesses. Also, because almost all of our patients are adults, paediatric patients were not included in this study. This group has distinctive symptoms, and the RIADT has the highest sensitivity in these patients. For this reason, applying similar research methods to different age groups may produce different results.

The US Center for Disease Control and Prevention suggested that the 2009 pandemic influenza A (H1N1) virus would continue to spread for years to come as a seasonal influenza virus. ${ }^{31}$ All the viruses detected in the current samples were 2009 pandemic influenza A (H1N1) or B. The sensitivity of RIADTs for 2009 pandemic influenza A (H1N1) virus was previously reported to be a little lower than that for influenza A (H3N2) virus, ${ }^{20}$ but in the current study, the sensitivity was equal for the two strains.

The reference, or 'gold,' standard in this study was not viral culture or RT-PCR but analysis using the Verigene test VRV, which detects influenza viral nucleic acid. When direct fluorescent antibody identification and viral culture were used as the gold standards, the sensitivity of the VRV system used in this study for influenza A was $98.7 \%$ (95\% CI $96.8 \%$ to $99.5 \%$ ) and the specificity was $93.2 \%$ (95\% CI $91.1 \%$ to $99.9 \%$ ). For influenza B, the sensitivity was $100 \%$ (95\% CI $91.8 \%$ to $100 \%$ ) and the specificity was $99.7 \% \quad(95 \%$ CI $99.1 \%$ to 99.9\%).${ }^{32}$ A reference standard was applied.

\section{CONCLUSIONS}

Consistent with previous reports, the sensitivity of the RIADT used in this study was low, due to early administration of the test. Administration of an RIADT too early 
after symptom onset causes FN results. In the influenza epidemic season, practitioners should not use RIADT for patients with upper respiratory symptoms and high fever for at least $12 \mathrm{~h}$ after onset. A positive RIADT result after this gives the physician firm support for a diagnosis of influenza. A negative RIADT result does not mean 'no influenza'. Presence of high fever and chills might predict influenza, but additional tests are necessary for patients with specific symptoms inconsistent with a diagnosis of influenza virus infection.

Acknowledgements The authors would like to thank Nanosphere for kindly providing the Verigene Respiratory Virus Plus Nucleic Acid Test (RVNAT) consumables and the Verigene System instrument.

Contributors MT, HY, KM, RS, YA, SB, Al, YU and TN were contributed to conception and design, acquisition of data or analysis and interpretation of data. MT was involved in drafting the article and HY, KM, SB, AI, KF, YU, HI, $\mathrm{KK}$ and TN were involved in revising it critically for important intellectual content. All the authors approved the final version of the article to be published.

Funding This study was supported in part by a Grant-in-Aid (S1201013) from the MEXT (Ministry of Education, Culture, Sports, Science and Technology) Strategic Research Foundation Project for Private Universities, 2012-2017.

Competing interests None.

Patient consent Obtained.

Ethics approval This study was reviewed and approved by the internal review boards of Juntendo University Hospital (approval number 22-290) and Juntendo Nerima Hospital (approval number 10-26).

Provenance and peer review Not commissioned; externally peer reviewed.

Data sharing statement No additional data are available.

Open Access This is an Open Access article distributed in accordance with the Creative Commons Attribution Non Commercial (CC BY-NC 3.0) license, which permits others to distribute, remix, adapt, build upon this work noncommercially, and license their derivative works on different terms, provided the original work is properly cited and the use is non-commercial. See: http:// creativecommons.org/licenses/by-nc/3.0/

\section{REFERENCES}

1. US Centers for Disease Control and Prevention. Influenza symptoms and the role of laboratory diagnosis. http://www.cdc.gov/flu/ professionals/diagnosis/larolesprocedures.htm (accessed 26 Nov 2012).

2. Mont AS, Gravenstein S, Elliott M, et al. Clinical signs and symptoms predicting influenza infection. Arch Intern Med 2000;160:3243-7

3. Call SA, Vollenweider MA, Hornung CA, et al. Does this patient have influenza? JAMA 2005;293:987-97.

4. Govaert TME, Dinant GJ, Aretz K, et al. The predictive value of influenza symptomatology in elderly people. Fam Pract 1998;15:16-22.

5. Walsh EE, Cox C, Falsey AR. Clinical features of influenza A virus infection in older hospitalized persons. J Am Geriatr Soc 2002;50:1498-503.

6. Bovin G, Hardy I, Teiler G. Predicting influenza infections during epidemics with use of a clinical case definition. Clin Infect Dis 2000;31:1166

7. Mitamura K, Sugaya N, Nirasawa M, et al. Impact of influenza $A$ virus infection as a cause of pediatric hospitalization and use of rapid antigen test of influenza A virus. Kansenshogaku Zasshi 1998;72:883-9.

8. Cooper NJ, Sutton AJ, Abrams KR, et al. Effectiveness of neuraminidase inhibitors in treatment and prevention of influenza $A$ and $B$ : systematic review and meta-analyses of randomised controlled trials. BMJ 2003;326:1235.
9. Fiore AE, Shay DK, Broder $\mathrm{K}$, et al. Prevention and control of influenza: recommendations of the Advisory Committee on Immunization Practices (ACIP), 2008. MMWR Recomm Rep 2008;57:1-60.

10. Hayden FG, Osterhaus A, Treanor JJ, et al. Efficacy and safety of the neuraminidase inhibitor zanamivir in the treatment of influenza virus infections. N Engl J Med 1997;337:874-80.

11. Jefferson $T$, Demicheli $V$, Rivetti $D$, et al. Antivirals for influenza in healthy adults: systematic review. Lancet 2006;367:303-13.

12. Jefferson $T$, Jones $M$, Doshi $P$, et al. Neuraminidase inhibitors for preventing and treating influenza in healthy adults: systematic review and meta-analysis. BMJ 2009;339:b5106.

13. Nicholson KG, Aoki FY, Osterhaus A, et al. Efficacy and safety of oseltamivir in treatment of acute influenza: a randomised controlled trial. Lancet 2000;355:1845-50.

14. Harper SA, Bradley JS, Englund JA, et al. Seasonal influenza in adults and children diagnosis, treatment, chemoprophylaxis, and institutional outbreak management: Clinical Practice Guidelines of the Infectious Diseases Society of America. Clin Infect Dis 2009;48:1003-32.

15. Hernan MA, Lipsitch M. Oseltamivir and risk of lower respiratory tract complications in patients with Flu symptoms: a meta-analysis of eleven randomized clinical trials. Clin Infect Dis 2011;53: 277-9

16. Kaiser L, Wat C, Mills T, et al. Impact of oseltamivir treatment on influenza-related lower respiratory tract complications and hospitalizations. Arch Intern Med 2003;163:1667-72.

17. Sugaya N, Shinjoh M, Mitamura K, et al. Very low pandemic influenza A (H1N1) 2009 mortality associated with early neuraminidase inhibitor treatment in Japan: analysis of 1000 hospitalized children. J Infect 2011;63:288-94.

18. US Centers for Disease Control and Prevention. Guidance for clinicians on the use of rapid influenza diagnostic tests. http://www. cdc.gov/flu/professionals/diagnosis/clinician_guidance_ridt.htm (accessed 26 Nov 2012).

19. Chartrand C, Leeflang MMG, Minion J, et al. Accuracy of rapid influenza diagnostic tests. A meta-analysis. Ann Intern Med 2012;156:500-11.

20. Sakai-Tagawa $Y$, Ozawa M, Tamura D, et al. Sensitivity of influenza rapid diagnostic tests to $\mathrm{H} 5 \mathrm{~N} 1$ and 2009 pandemic $\mathrm{H} 1 \mathrm{~N} 1$ viruses. J Clin Microbiol 2010;48:2872-7.

21. Weekly reports of influenza virus isolation/detection, from week 36 of 2010 to week 19 of 2011 , Japan. http://idsc.nih.go.jp/iasr/prompt/ graph/sinin1e-1.gif (accessed 30 Oct 2013)

22. The attachment of RapidTesta FLU II (Sekisui Medical, Tokyo, Japan), http://www.eidia.co.jp/product/diagnose/attach/attach pdf/ ippan/rapid-flu-2.pdf (accessed 30 Oct 2013).

23. Takahashi H, Otsuka Y, Patterson BK. Diagnostic tests for influenza and other respiratory viruses: determining performance specifications based on clinical setting. $J$ Infect Chemother 2010;16:155-61.

24. Boku S, Naito T, Murai K, et al. Near point-of-care administration by the attending physician of the rapid influenza antigen detection immunochromatography test and the fully automated respiratory virus nucleic acid test: contribution to patient management. Diagn Microbiol Infect Dis 2013;76:445-9.

25. Treanor JJ. Influenza virus. In: Mandell GL, Bennett JE, Dolin R. eds. Principles and practice of infectious diseases, 7th edn. Philadelphia: Churchill Livingstone, 2005:2276.

26. Landry ML, Cohen S, Ferguson D. Real-time PCR compared to Binax NOW and cytospin immunofluorescence for detection of influenza in hospitalized patients. J Clin Virol 2008;43:148-51.

27. McGeer AJ. Diagnostic testing or empirical therapy for patients hospitalized with suspected influenza: what to do? Clin Infect Dis 2009;48:S14-19.

28. Treanor JJ. Influenza virus. In: Mandell GL, Bennett JE, Dolin R eds. Principles and practice of infectious diseases, 7th edn. Philadelphia: Churchill Livingstone, 2005:2271-2.

29. Ebell MH, White LL, Casault T. A systematic review of the history and physical examination to diagnose influenza. J Am Board Fam Pract 2004;17:1-5.

30. Tokuda $\mathrm{Y}$, Miyasato $\mathrm{H}$, Stein $\mathrm{GH}$, et al. The degree of chills for risk of bacteremia in acute febrile illness. Am J Med 2005;118:1417.

31. US Centers for Disease Control and Prevention. 2009 H1N1 Situation Update. http://www.cdc.gov/h1n1flu/ (accessed 20 Jun 2013).

32. FDA 510(k) Summary of K103209: Verigene Respiratory Virus Plus Nucleic Acid Test on the Verigene System (RV+). http://www accessdata.fda.gov/cdrh docs/pdf10/K103209.pdf (accessed 30 Oct 2013) 